\title{
28 Research Soure \\ COVID-19 Associated Cerebral Infarction in an Elderly Patient: A Case Report
}

\section{Jumin Xie}

Medical college of Hubei Polytechnic University https://orcid.org/0000-0002-4493-4548

\section{Changwu Feng}

Hubei Polytechnic University

Jie Chen

Hubei Polytechnic University

Zhu Wang ( $\nabla$ wangzhu912100@163.com )

Huangshi Central Hospital

\section{Case report}

Keywords: SARS-Cov-2, COVID-19, cerebral infraction, elderly patient, case report

Posted Date: January 9th, 2021

DOl: https://doi.org/10.21203/rs.3.rs-139941/v1

License: (c) (i) This work is licensed under a Creative Commons Attribution 4.0 International License. Read Full License 


\section{Abstract}

Background: The 2019 Severe Acute Respiratory Syndrome Coronavirus (SARS-Cov-2) had been declared an emergency at the beginning and eventually progressing to a pandemic by World Health Organization. To date, more than $78,194,9471$ people confirmed infected by SARS-Cov- 2 and 1,736,752 dead, globally. Various characteristics were described in the case reports and clinical studies after SARS-Cov-2 hitting the whole world.

Case presentationखCOVID-19 cases accompanied with cerebral infraction were hardly reported. Herein, we present a 74-yesrs-old patient who got SARS-Cov-2 infected at the late January and developed cerebral infraction. After accurate treatment, the old patient recovered and discharged from hospital on April 3, 2020. We keep on supervising the patient, after 7 months long physical condition surveillance, the patient live a normal life with on obvious sequelae detected.

Conclusions: In this paper, we present a elder COVID-19 case associated with cerebral infraction and whole process management in treatment. The elder patients lived a normal life after discharging from Huangshi central hospital which we believed that early introducing of traditional Chinese medicine played important roles in COVID-19 treatment. We aimed to broaden new cognition towards SARS-Cov-2 infection and suggest therapy to COVID-19 cases with cerebral infraction.

\section{Introduction}

Breaking severe pneumonia caused by novel severe acute respiratory syndrome coronavirus 2 (SARS-Cov2) spreads to 220 countries, areas or territories worldwide. More than $78,194,9471$ people confirmed infected and 1,736,752 deceased according to WHO. Coronavirus disease (COVID-19) pandemic has made enormous loss in economy and huge threaten to people's life and health, globally. SARS-Cov-2 was classified as betacoronavirus genus associated with 229E, OC43, NL63, HKU1, severe acute respiratory syndrome coronavirus (SARS-Cov) and Middle East respiratory syndrome coronavirus (MERS-Cov)[1, 2].

SARS-Cov-2 is an enveloped positive-sense RNA virus and belongs to the seventh member of coronavirus. SARS-Cov-2, together with SARS-Cov and MERS-Cov, could cause fatal pneumonia in human[2]. Studies have proved that spike protein of SARS-Cov-2 is the molecular determinant of viral attachment, fusion, and entry into host cells[3, 4]. SARS-Cov-2 spike protein combines to angiotensin-converting enzyme 2 (ACE2), and in concert with principally transmembrane serine protease 2 (TMPRSS2), promotes cellular entry[5]. Structure of the spike protein receptor-binding domain (RBD) had been determined, meanwhile essential residues had been figured out in ACE2 binding[6, 7]. SARS-Cov-2 shows high genetic similarity to RaTG13 with a 93.1\% nucleotides identity which was isolated from bat in 2013[1]. Phylogenetic analysis of SARS-Cov-2 genome elucidated high probability of natural occurring and bat origin[1]. Analysis of residues in SARS-Cov-2 RBD showed highly conserved amino acids and side chain properties with those in SARS-Cov RBD for ACE2 binding[8]. 
A variety of characteristics related to COVID-19 appeared in the latest months in all ages, clinically, and these typical symptoms include fever, cough, headache, fatigue, gastrointestinal symptoms, chest tightness or dyspnea[9]. In this paper, we presented a 74 years old man with COVID-19 infection who developed cerebral infarction and encephalatrophy at the early stage of SARS-Cov-2 pandemic in Huangshi, China. Then this patient was confirmed SARS-Cov-2 infection with throat swab testing positive by real-time PCR. With a month long treatment, the patient recovered from COVID-19 with at least three times viral nucleic acid testing negative and discharged from hospital on April 3, 2020. After five month's surveillance, the patient is totally cured and the physical condition is good without diagnostic sequelae.

\section{Case Presentation}

A 74-year-old male patient was sent to Huangshi hospital of Traditional Chinese Medicine on January 31, 2020 , with two days long of fever, cough, headache, diarrhea, vomiting, fatigue and dyspnea. Those characteristics, weakness in the right extremities, distortion of commissure and lalopathy had already emerged at middle January.

Blood tests revealed elevated monocyte counts $(0.64 \mathrm{~g} / \mathrm{L}$, [normal, $0.10-0.60 \mathrm{~g} / \mathrm{L}])$, mean platelet volume (12.00 fL, [normal, 8.50-11.80 fL]) and percentage of monocyte (16.30\%, [normal, 3.00-10.00\%]), nevertheless eosinophil count $(0.00 \mathrm{~g} / \mathrm{L}$, [normal, $0.02-0.52 \mathrm{~g} / \mathrm{L}$ ]), percentage of eosinophil $(0.00 \%$, [normal, $0.40-8.00 \%]$ ), blood platelet count ( $87 \mathrm{~g} / \mathrm{L}$, [normal, $125-350 \mathrm{~g} / \mathrm{L}])$, mean corpuscular hemoglobin concentration (315 g/L, [normal, 316-354 g/L]) and hemoglobin concentration $(129 \mathrm{~g} / \mathrm{L}$, [normal, 130-175 g/L]) lowered on February 3, 2020. Throat swab was taken to detect respiratory tract pathogens after blood testing and listed in Table 1. Coagulation profiles were tested and showed in Table 2. D-dimer and Fibrinogen degradation products increased a lot compared with normal reference range while other items were normal. As 80 kilometers away from COVID-19 outbreak site, Wuhan, SARS-Cov-2 RNA testing was unavailable in early February in Huangshi hospital of Traditional Chinese Medicine. We speculated that he got SARS-Cov-2 infected, then he was send to thoracic computed tomography (CT) diagnosis. 
Table 1

Respiratory tract pathogens PCR detection.

\begin{tabular}{|lll|}
\hline Items & Results & Ref range \\
\hline Legionella pneumophila & Not detected (Negative) & Negative \\
\hline Mycoplasma pneumoniae & Not detected (Negative) & Negative \\
\hline Q hot rickettsia & Not detected (Negative) & Negative \\
\hline Chlamydia pneumoniae & Not detected (Negative) & Negative \\
\hline Adenoviridae & Not detected (Negative) & Negative \\
\hline Respiratory syncytial virus & Not detected (Negative) & Negative \\
\hline Influenza A virus & Not detected (Negative) & Negative \\
\hline Influenza B Virus & Not detected (Negative) & Negative \\
\hline Parainfluenza virus & Not detected (Negative) & Negative \\
\hline
\end{tabular}

Table 2

Coagulation profiles

\begin{tabular}{|llll|}
\hline Items & Results & Unit & Ref range \\
\hline prothrombin time & 11.60 & $\mathrm{~S}$ & $9.00-14.00$ \\
\hline International normalized ratio of prothrombin time & 0.91 & - & $0.85-1.15$ \\
\hline Activated partial thromboplastin time & 27.3 & $\mathrm{~S}$ & $20.0-41.0$ \\
\hline Thrombin time & 12.2 & $\mathrm{~S}$ & $8.0-14.0$ \\
\hline Fibrinogen & 3.98 & $\mathrm{~g} / \mathrm{L}$ & $2.00-4.00$ \\
\hline D-dimer & 4.81 & $\mu \mathrm{g} / \mathrm{mL}$ & $0-0.50$ \\
\hline Fibrinogen degradation products & 143.25 & $\mu \mathrm{g} / \mathrm{L}$ & $0-5.00$ \\
\hline
\end{tabular}

Thoracic CT scan showed ground-glass opacities in the right and left middle lobes, indicating the possibility of viral pneumonia on February 5, 2020 (Fig. 1). Based on the diagnosis, he was hospitalized for further investigation of suspected COVID-19. Based on the CT scanning results and clinical features, antiretroviral, antispasmodic and antiasthmatic expectorant therapy were given to the patient.

On February 7, thoracic CT scan showed aggravation of ground-glass opacities in both lobes (Fig. 2) compared to results on February 5. Blood tests On February 7 showed increased neutrophile granulocyte count and ratio which indicated pathogenic infection. On February 9, blood tests showed elevated WBC count, neutrophile granulocyte count and ratio, and monocyte count while percentage and count of eosinophil and lymphocyte lowered. Since lack of SARS-Cov-2 RNA testing products at that special time in Huangshi in early February, no nucleic acid results could provide diagnosis of COVID-19. 
Coagulation profiles were tested on February 10, 14, 20, 24, 25, March 1, 2, 5, 10, 14 and 20, among the items D-dimer (Normal range, 0-0.50 $\mu \mathrm{g} / \mathrm{mL}$ ) all overstepped except March 20 (Fig. 3). Previous studies demonstrated that D-dimer levels were a vital indicator in predicting COVID-19 infection and in-hospital mortality[10]. In early stage of viral infection, D-dimer value was $4.81 \mu \mathrm{g} / \mathrm{mL}$ which increased a lot compared with normal range. We then investigated the prothrombin time (PT), thrombin time (TT) and fibrinogen $(\mathrm{Fg})$ which were also significant indicators in confirmation of COVID-19 infection. PT and Fg elevated in the middle infection period, while TT increased in the early stage (Fig. 4).

In the middle of February, all of a sudden, the patient got right limb weakness accompanied with crooked mouth, speech barriers and other discomfort. Then the patient was sent to cranial CT detection on February 20 and 26, and cranial CT scan showed cerebral infarction in bilateral basal ganglia area, radial coronal area and bilateral frontal parietal lacunar, partial softening lesion formation and leukoencephalopathy and brain atrophy (Figs. 5 and 6). Anti-infection, anti-platelet aggregation and circulation improving treatment were given to the patient.

Through asking, we know the patient had a history of hypertension and type 2 diabetes. Physical examination showed blood pressure $135 / 80 \mathrm{mmHg}$, heart beats 80 times/min, body temperature $37^{\circ} \mathrm{C}$, no yellowing in the whole skin, no lymph nodes enlargement in the superficial layer, clear respiratory sound in both lungs, no rales and dryness in both lungs, regular heart rhythm, no murmurs, flat and soft abdomen, and no swelling in both lower extremities. Three-dimensional reconstruction of the lungs, mediastinum, heart and ribs showed both lungs of viral infection, calcification of aorta and coronary artery wall, arteriosclerosis, increased and enlarged lymph nodes in the mediastinum and local adhesion of the pleura of both lungs, multiple local circular light-transmitting areas in the lower lobe of both lungs and emphysema with interstitial pneumonia on February 22. Compared with chest CT on February, the lesions in the upper lobe of left lung and the lower lobe of right lung expanded, while the lesions in the lower lobe of left lung and the upper lobe of right lung narrowed

SARS-Cov-2 antibodies were tested on March 1, II IgG, 123.64 AU/mL, II IgM $16.89 \mathrm{AU} / \mathrm{mL}$, these indexes exceeded the normal range $(0-10.00 \mathrm{AU} / \mathrm{mL})$. On March 3, the patient was transferred to Huangshi Central Hospital for systemic detection and treatment. On March 5, both II IgG and II IgM were detected once more, IgG was $77.80 \mathrm{AU} / \mathrm{mL}$ which elevated a lot compared with norm, while II IgM gained 5.72 $\mathrm{AU} / \mathrm{mL}$ which located at normal range. The positive of SARS-Cov-2 II IgG together with CT results confirmed the SARS-Cov-2 pneumonia.

On admission, the patient suffers from fever, cough, head pain and dyspnea, as of COVID-19 epidemic, we firstly used anti-viral therapy. As the physical condition was getting better, we tended to additional detection. Cerebral CT scan showed cerebral infarction and encephalatrophy symptoms on March 10, and the situation got worse on March 16. Pulmonary function test and evaluation showed delightful consequence and PCR confirmed SARS-Cov-2 negative on March 19. Body temperature was $36.5^{\circ} \mathrm{C}$, and blood pressure was $120 / 75 \mathrm{~mm} \mathrm{Hg}$, with a respiratory of 19 breaths per minute and heart rate of 75 beats 
per minute. He had no cough, dyspnea t rest, chest distress and shortness of breath, chest pain, gasp and ventilator assistance. oxyhemoglobin saturation reached $100 \%$.

Recommended medication guides were suggested as follows, for antiplatelet aggregation (Clopidogrel hydrogen shlfate tablet $25 \mathrm{mg}$ po qd), for lowering blood lipid and stabilizing plaque (Rosuvastatin $5 \mathrm{mg}$ po qd), for controlling heart rate and protecting heart muscle (Metoprolol tartrate controlled-release tablet $25 \mathrm{mg}$ po qd), for controlling blood pressure (Felodipine sustained release tablet $5 \mathrm{mg}$ po qd), for dissipating phlegm (Acetylcysteine Effervescent Tablets $0.6 \mathrm{~g}$ po bid), for antiviral infection (Imipenemastatin $0.5 \mathrm{~g} \mathrm{IV}$ ) and accompanied with rehabilitation training therapy (PT OT therapy).

On March 21, the patient told brief palpitation, but vital signs were stable. Soon myo-cardial enzymonram were dectected, troponin $(0.01 \mathrm{ng} / \mathrm{mL})$ and $B$ natriuretic sodium $(50 \mathrm{pg} / \mathrm{mL})$ both demonstrated normal. SARS-Cov-2 nucleic acid testing proved negative on March 31. The patient was physically stable and allowed discharged from hospital on April 3. In the following months, we kept on supervising the patient's physical conditions regularly, and no obvious sequela showed.

\section{Discussion}

WHO has declared COVID-19 a pandemic on March 11, 2020. As confirmed and dead cases grow sustainably, SARS-Cov-2 has caused enormous loss in global public health and economy. Currently, several reports have proved that SARS-Cov-2 affects cerebral neurons resulting in insomnia, headache, stroke, mild cognitive impairment, epilepsy and encephalorrhagia[11, 12]. As we all know that severe acute respiratory syndrome coronavirus (SARS) influences nervous system and induces polyneuropathy, encephalitis, ischemic stroke[13,14]. SARS-Cov-2 shares $79.5 \%$ genetic similarity to SARS and main infection sites are lung[1]. Similarity in structure of RBDs for improved binding to ACE2 and genome sequence strongly demonstrate convergent evolution between the SARS-CoV-2 and SARS-CoV, although SARS-CoV-2 which belongs to beta-clade does not cluster within SARS and SARS-related coronaviruses[15]. After being infected with SARS-Cov-2, people got similar symptoms as SARS-Cov infection.

We firstly report this case that the elder patient who got SARS-Cov-2 infected associating with cerebral infarction. Whether SRAS-Cov-2 entries and damages central nervous system remains elusive, more research need to be done to investigate this perspective. Most recently, SARS-Cov-2 has been reported viral infection of human neural progenitor cells and brain organoid[16]. SARS-Cov-2 is not only a respiratory virus which infects lung with fever, dry cough, and acute pneumonia as the primary symptoms, but also infects epithelial cells expressing angiotensin converting enzyme 2 (ACE2) receptor[17]. SARS-Cov-2 binds ACE2 which is crucial for viral entry and blood pressure regulation[18]. ACE2 receptor is present in many organs which facilitates virus spreading in human body and also increases viral transmission. Determination of crystal structure of the receptor-binding domain (RBD) of the spike protein of SARS-CoV-2 facilitates the understanding of viral combination, entry and meanwhile provides guidance for intervention strategies that target receptor recognition by SARS-CoV-2[3]. 
The patient discharged from Huangshi Central Hospital on April 3, 2020 after the systemic comprehensive evaluation which included breathing rate, oxyhemoglobin saturation, walking test, and limbs coordination.

We continuously supervise the patient until now after discharging from hospital. Physiological indicators are back to normal except the sequelae after cerebral infarction. During surveillance period, blood tests, breathing rate, oxyhemoglobin saturation were detected regularly and exhibited normal. No positive SARS-Cov-2 testing are shown.

\section{Conclusion}

Previous reports have mentioned that COVID-19 could cause encephalitis, headache, stroke, mild cognitive impairment, epilepsy and encephalorrhagia in the brain. Hitherto no obvious evidences proved that SARS-Cov-2 infecting brain cause damaging, more proofs and researches need to confirm the association between cerebral injure and COVID-19.

Clinical cerebral infraction in COVID-19 confirmed cases are limited. Early diagnosis of cerebral infraction of COVID-19 could shed light on patient treatment and medicinal guidance. We report a successful recovery cases of COVID-19 associated with cerebral infraction who is 74-years old which could provide appropriate guidance for correlated cases recovery. After discharging from hospital, this elder patient lived a normal life without sequelae for the following months which we believed that introducing of traditional Chinese herbs in early medication played pivotal roles in COVID-19 treatment.

\section{Abbreviations}

SARS-Cov-2 Severe Acute Respiratory Syndrome coronavirus 2

CT Computed tomography

RBD receptor-binding domain

ACE2 angiotensin-converting enzyme 2

PT prothrombin time

TT thrombin time

Fg fibrinogen

\section{Declarations}

\section{Ethics approval and consent to participate}


The Ethics Committee of Huangshi Central Hospital confers this case report submission and participating in BMC neurology. The patient would love to share his medical experiences and consent for this case report submission.

\section{Consent to publish}

The Ethics Committee of Huangshi Central Hospital confers this case report publication in BMC neurology

\section{Availability of data and materials}

Availability of data and materials should address to Wangzhu912100@163.com

\section{Competing interest}

The authors declare that they have no competing interest.

\section{Funding}

This study was supported by Fund of Hubei Provincial Department of Education (Q20204508) and Talent Introduction Project of Hubei Polytechnic University (19XJK02R).

\section{Authors' contribution}

J. X wrote the manuscript. C. F helped in data analysis and shared the case report. Z.W participates in patient's treatment and rehabilitation, meanwhile he shared all the testing data of the patient. J. C gave critical suggestions in manuscript writing.

\section{Acknowledgement}

We thank the patient for his kind permission and willing to share the experiences.

\section{ORCID IDs}

Jumin Xie https://orcid.org/0000-0002-4493-4548

Changwu Feng https://orcid.org/0000-0002-3348-1336

Jie Chen https://orcid.org/0000-0002-7192-7677

Zhu Wang https://orcid.org/0000-0003-2608-6968

\section{References}

1. Zhou P, Yang XL, Wang XG, Hu B, Zhang L, Zhang W, et al. A pneumonia outbreak associated with a new coronavirus of probable bat origin. Nature. 2020;579 7798:270-3. doi:10.1038/s41586-020- 
2012-7.

2. Zhu N, Zhang D, Wang W, Li X, Yang B, Song J, et al. A Novel Coronavirus from Patients with Pneumonia in China, 2019. N Engl J Med. 2020;382 8:727-33. doi:10.1056/NEJMoa2001017.

3. Yan R, Zhang Y, Li Y, Xia L, Guo Y, Zhou Q. Structural basis for the recognition of SARS-CoV-2 by fulllength human ACE2. Science. 2020;367 6485:1444-8. doi:10.1126/science.abb2762.

4. Shang J, Ye G, Shi K, Wan Y, Luo C, Aihara H, et al. Structural basis of receptor recognition by SARSCoV-2. Nature. 2020;581 7807:221-4. doi:10.1038/s41586-020-2179-y.

5. Ziegler CGK, Allon SJ, Nyquist SK, Mbano IM, Miao VN, Tzouanas CN, et al. SARS-CoV-2 Receptor ACE2 Is an Interferon-Stimulated Gene in Human Airway Epithelial Cells and Is Detected in Specific Cell Subsets across Tissues. Cell. 2020;181 5:1016-35.e19. doi:10.1016/j.cell.2020.04.035.

6. Walls AC, Park YJ, Tortorici MA, Wall A, McGuire AT, Veesler D. Structure, Function, and Antigenicity of the SARS-CoV-2 Spike Glycoprotein. Cell. 2020;181 2:281 - 92.e6; doi:10.1016/j.cell.2020.02.058.

7. Wang Q, Zhang Y, Wu L, Niu S, Song C, Zhang Z, et al. Structural and Functional Basis of SARS-CoV-2 Entry by Using Human ACE2. Cell. 2020;181 4:894-904.e9. doi:10.1016/j.cell.2020.03.045.

8. Lan J, Ge J, Yu J, Shan S, Zhou H, Fan S, et al. Structure of the SARS-CoV-2 spike receptor-binding domain bound to the ACE2 receptor. Nature. 2020;581 7807:215-20. doi:10.1038/s41586-020-21805 .

9. Wang D, Hu B, Hu C, Zhu F, Liu X, Zhang J, et al. Clinical Characteristics of 138 Hospitalized Patients With 2019 Novel Coronavirus-Infected Pneumonia in Wuhan, China. Jama. 2020. doi:10.1001/jama.2020.1585.

10. Zhang L, Yan X, Fan Q, Liu H, Liu X, Liu Z, et al. D-dimer levels on admission to predict in-hospital mortality in patients with Covid-19. J Thromb Haemost. 2020;18 6:1324-9. doi:10.1111/jth.14859.

11. Adan GH, Mitchell JW, Marson T. Epilepsy care in the COVID-19 era. Clin Med (Lond). 2020;20 4:e104e6. doi:10.7861/clinmed.2020-0207.

12. Aghagoli G, Gallo Marin B, Katchur NJ, Chaves-Sell F, Asaad WF, Murphy SA. Neurological Involvement in COVID-19 and Potential Mechanisms: A Review. Neurocrit Care. 2020:1-10; doi: 10.1007/s12028-020-01049-4.

13. Liang JW, Reynolds AS, Reilly K, Lay C, Kellner CP, Shigematsu T, et al. COVID-19 and Decompressive Hemicraniectomy for Acute Ischemic Stroke. Stroke. 2020:trokeaha120030804; doi:10.1161/strokeaha.120.030804.

14. Zhai P, Ding Y, Li Y. The impact of COVID-19 on ischemic stroke. Diagn Pathol. 2020;15 1:78. doi:10.1186/s13000-020-00994-0.

15. Wu F, Zhao S, Yu B, Chen YM, Wang W, Song ZG, et al. A new coronavirus associated with human respiratory disease in China. Nature. 2020;579 7798:265-9. doi:10.1038/s41586-020-2008-3.

16. Zhang BZ, Chu H, Han S, Shuai H, Deng J, Hu YF, et al. SARS-CoV-2 infects human neural progenitor cells and brain organoids. Cell Res. 2020. doi:10.1038/s41422-020-0390-x. 
17. Jiang RD, Liu MQ, Chen Y, Shan C, Zhou YW, Shen XR, et al. Pathogenesis of SARS-CoV-2 in Transgenic Mice Expressing Human Angiotensin-Converting Enzyme 2. Cell. 2020;182 1:50 - 8.e8; doi:10.1016/j.cell.2020.05.027.

18. Watanabe Y, Allen JD, Wrapp D, McLellan JS, Crispin M. Site-specific glycan analysis of the SARSCoV-2 spike. Science. 2020;369 6501:330-3. doi:10.1126/science.abb9983.

\section{Figures}

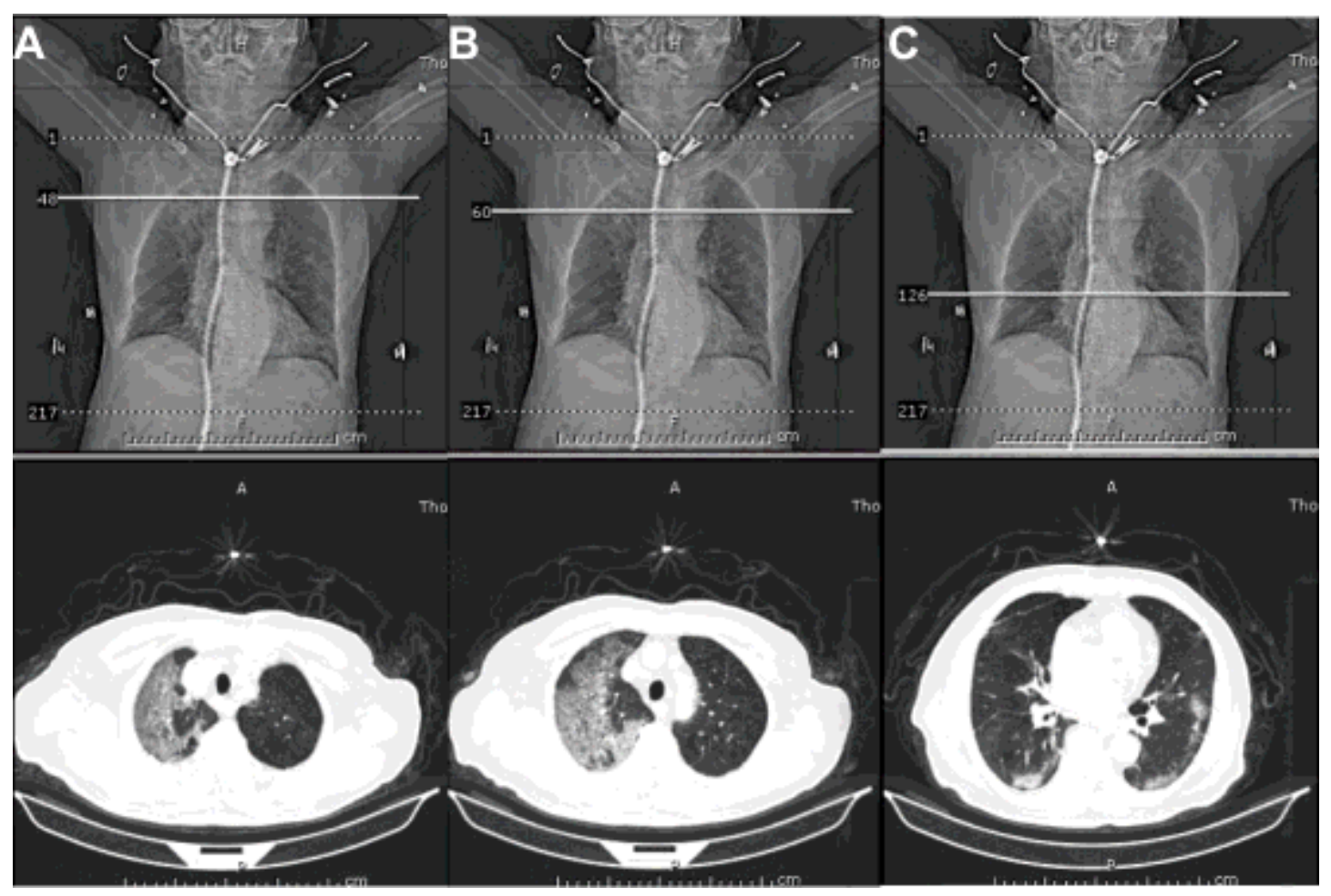

\section{Figure 1}

Thoracic CT scan results on February 5, 2020. (A), (B) and (C) showed different lung positions with obvious ground-glass opacity. 


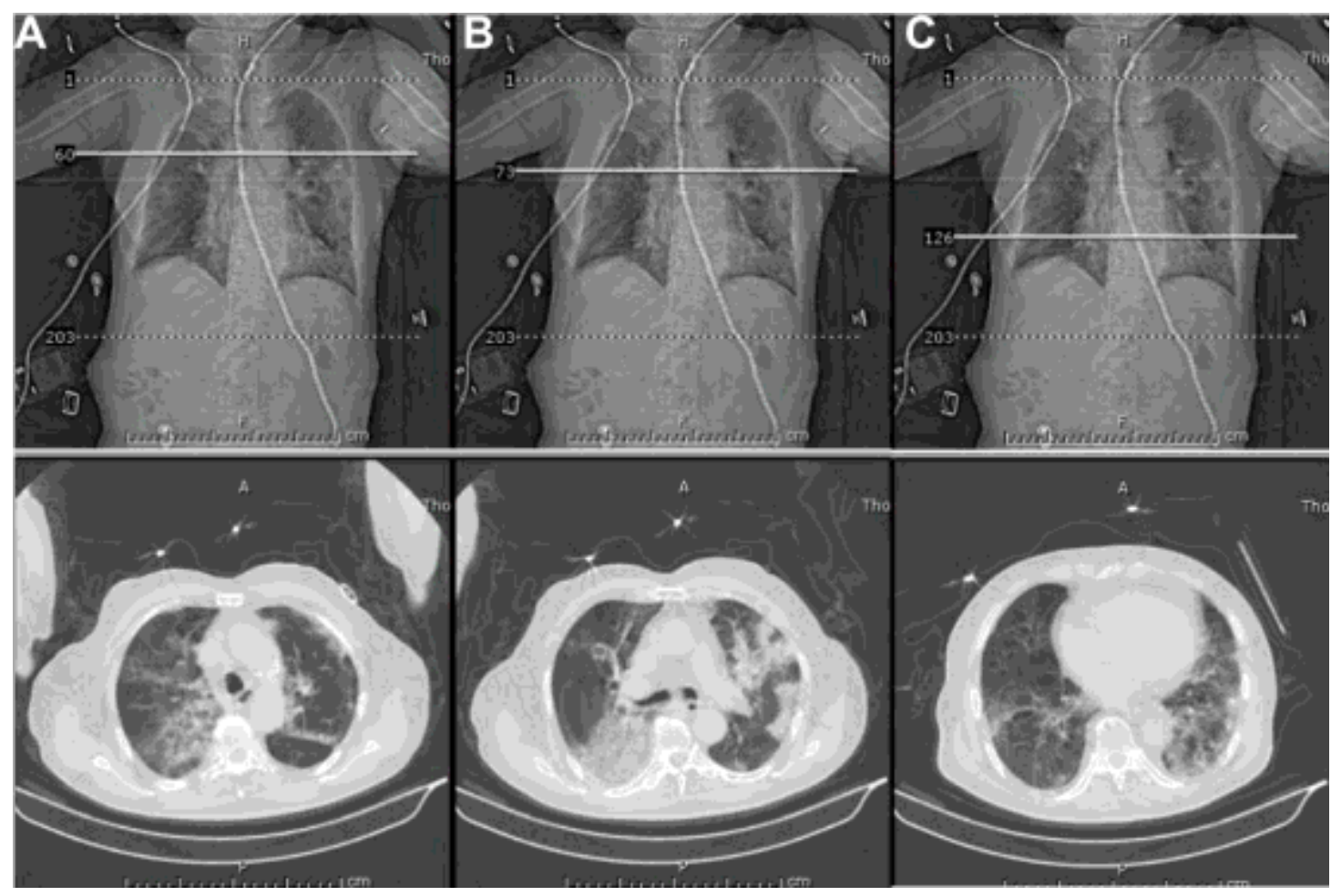

\section{Figure 2}

Thoracic CT scan results on February 7, 2020. (A), (B) and (C) showed different lung positions with obvious ground-glass opacity. Aggravation of ground-glass opacity in both lobes compared with CT scan results on February 5, 2020.

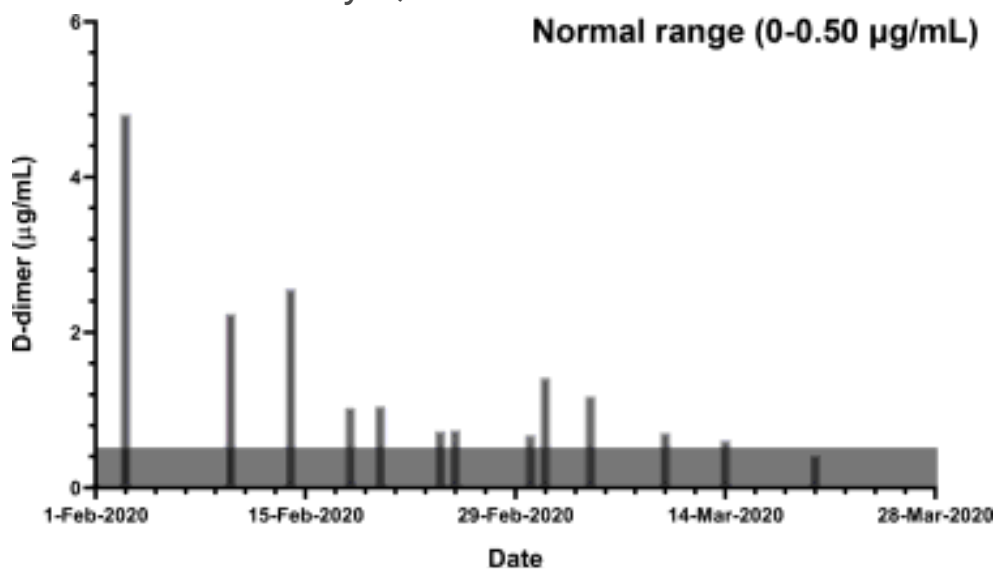

Figure 3

D-dimer values in each coagulation profiles detected in distinctive dates during hospitalization. 


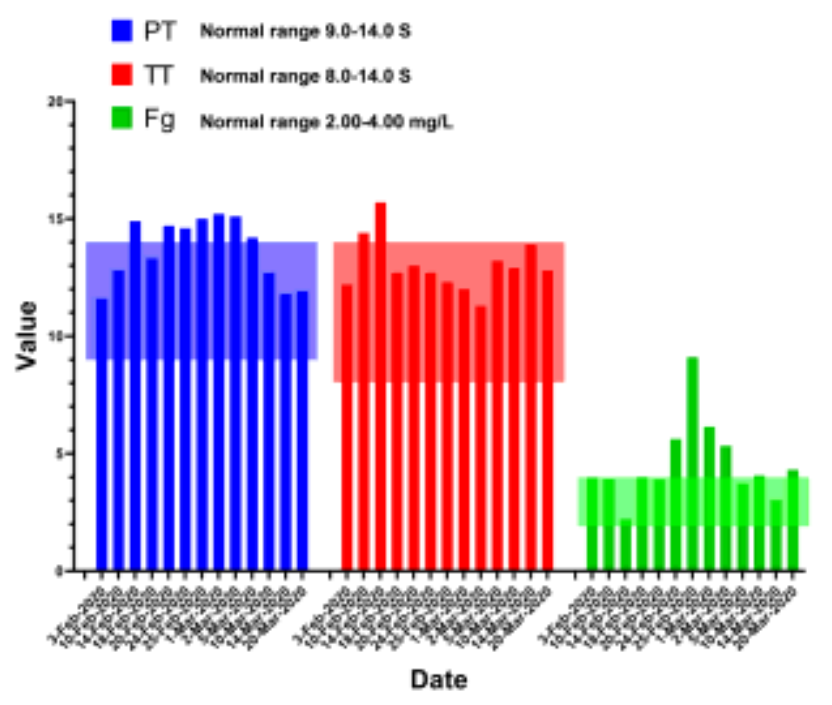

Figure 4

PT, TT and Fg values in each coagulation profiles detected in distinctive dates during hospitalization. 


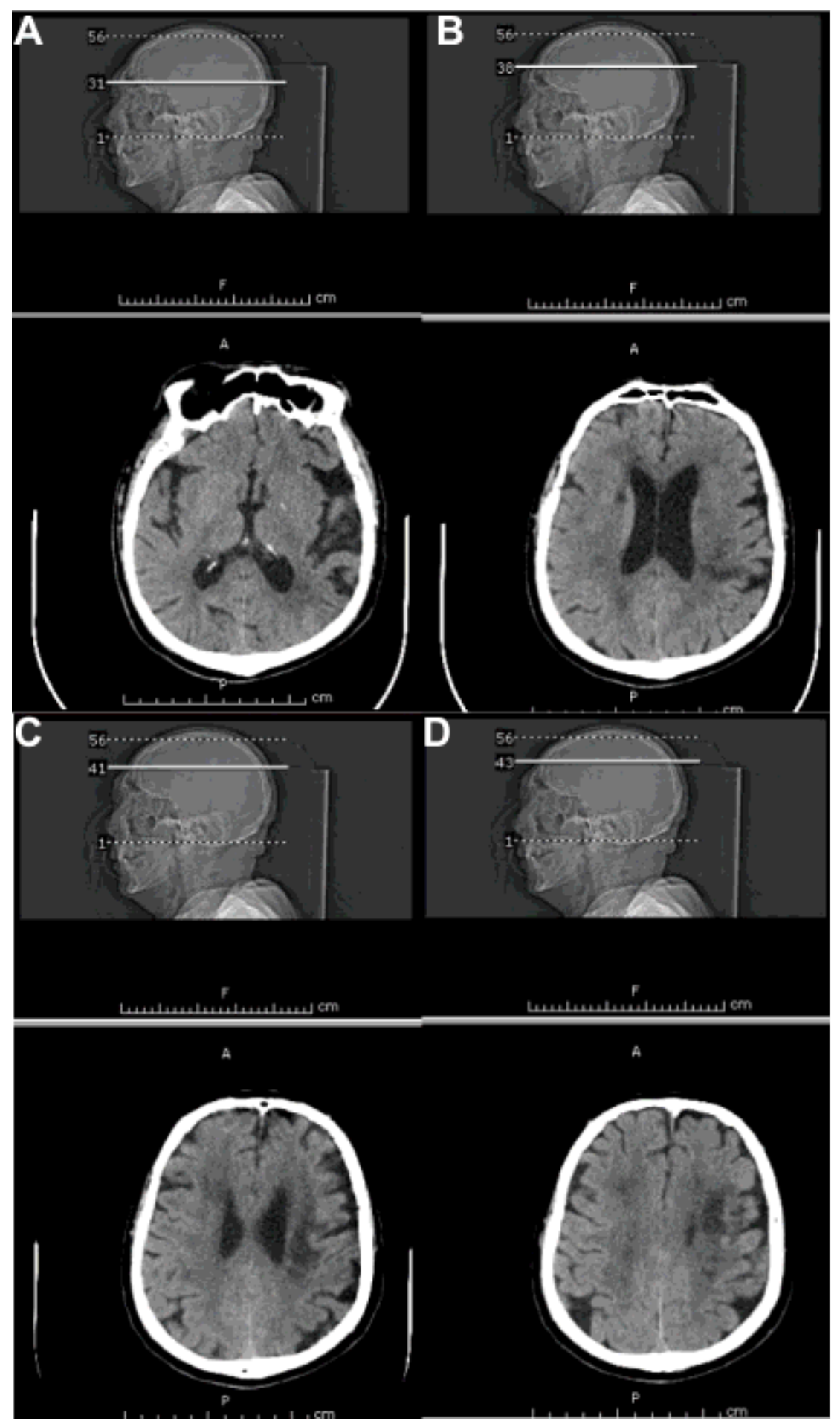

Figure 5

Cranial CT scan results on February 20, 2020. 

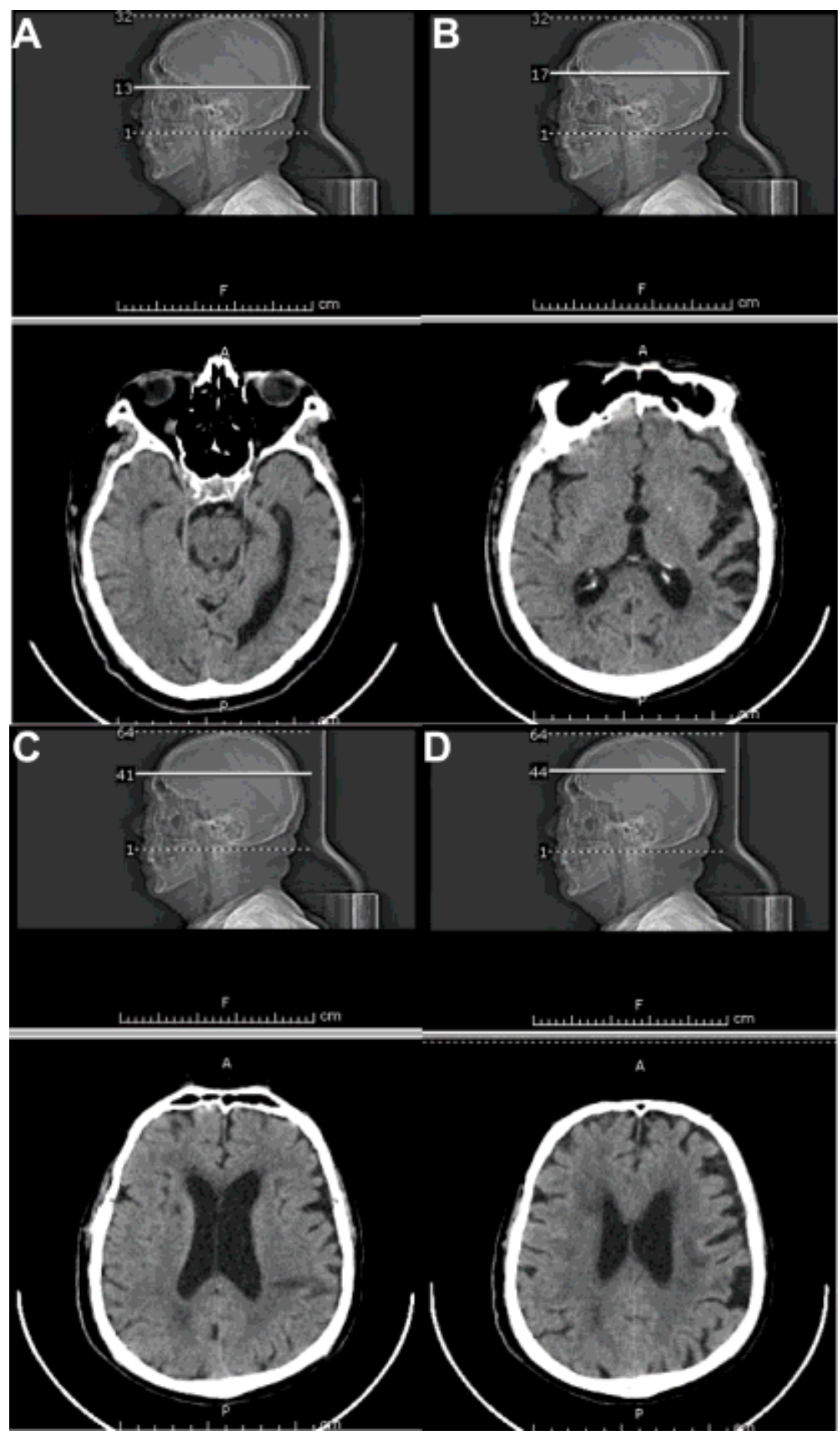

Figure 6

Cranial CT scan results on February 26, 2020. 